\title{
GERMAN MIGRANTS IN BULGARIA AND THEIR SOCIAL NETWORKS
}

\author{
Tanya Matanova \\ Assistant Professor \\ Institute of Ethnology and Folklore Studies with Ethnographic Museum \\ Bulgarian Academy of Sciences, Bulgaria \\ tmatanova@gmail.com
}

\begin{abstract}
Recent researches have shown that there were about 7,300 German citizens with a valid Bulgarian registration certificate in Bulgaria at the end of 2017. This paper introduces several facts and observations about some of them, gathered during a pilot study between 2017 and 2019. Besides the classical ethnographic methods of conducting 40 interviews and observing gatherings, the methods of social network analysis, virtual ethnography and netnography have also been applied as research tools. On the whole, it can be said that Germans come to Bulgaria for different reasons; according to their motives they can be classified as labor, student, family, and retirement migrants. They all tend to create community structures, the less informal of which are social network groups. Modern social media tools provide an opportunity to form virtual groups through different internet-based networks. The results of the research show that the most popular and the most frequently used among the virtual groups are Facebook groups. The research analyzed 16 Facebook groups concerned with the life of German migrants in Bulgaria. Some of them were formed in order to share information about events related to the German community as well as to the folklore and cultural landscapes of Bulgaria. Other Facebook groups facilitate the communication regarding the organization of meetings (such as a Stammtisch, i.e. round-table with fellow regulars) outside the virtual space. Social network analysis can also be done from an ego-centered perspective, when we analyze the social network of a given person with the ego in the center, his/her alteri (the persons connected with the ego) in the periphery, and the relational ties between them. We can thus obtain information about other people (friends, relatives, colleagues, etc.) in their everyday life and the interaction with them through face-to-face and online communication. Data about the egocentric social networks of seven respondents has been obtained through the program VennMaker. The analyses show their social networks' alteri, including their ethnic origin and type of relationship.
\end{abstract}

Keywords: Germans in Bulgaria, personal social networks, social network analysis, virtual social networks, virtual ethnography 


\section{INTRODUCTION: GERMANS IN BULGARIA}

Since Bulgaria became part of the European Union in 2007, more and more Germans from different parts of their country have come to Bulgaria, driven by a desire to emigrate. In 2015, according to Eurostat, Bulgaria was one of the countries in the European Union with the lowest number of people coming from the countries of the EU (Immigrants 2017). To the latter belong also Germans, who see Bulgaria as an attractive destination for a new home. They have moved there since the end of the twentieth century as the life in the homeland or in previous immigration countries such as Spain, Portugal, and Italy has become more expensive and the lands have been overcrowded with migrants from Germany, the United Kingdom, and Scandinavian countries.

Concerning the numbers of Germans in Bulgaria, there were about 850 German citizens in Bulgaria according to the 2011 Census. Recent studies on German citizens with a valid Bulgarian registration certificate show that at the end of 2017 the number was about 7,300 (Matanova 2019: 86). Germans in Bulgaria can be divided into four categories according to the nature of emigration: mixed marriage, study, labor, and retirement migration. Among mixed marriages there are German-Bulgarian couples who have been married for more than twenty years and have come to live in Bulgaria after a period of living in Germany. This category also comprises newcomers who choose to live in Bulgaria (most often) with a Bulgarian wife (the husband is seldom Bulgarian) whom they have met during a holiday in the same country.

Many of the interviewees of the current study on migration were medical students at Bulgarian universities in Varna, Plovdiv, and Sofia. More and more Germans at retirement age are willing to live outside of their homeland, due to dissatisfaction with the political situation in Germany or because of their low retirement benefits on which, as they say, they cannot live, but just survive. The youngest emigrant group ${ }^{1}$ are Germans who came mostly after the accession of Bulgaria to the European Union and the opening of branches of German companies there; the labor migrants live mainly in Sofia and Plovdiv. In general, Germans prefer the capital and other district cities, if possible, close to the sea or in areas with a warmer climate and fresh air. A considerable number of them settle down in small villages where some of their compatriots already live (here we can speak of a chain migration; however, it is based on ethnic and national origin, not on family or friendship relations). Thus, they build German subgroups around given social or cultural features - origin, age group, gender, language, etc. (see Maeva 2017: 17; Entzinger \& Biezeveld 2003). 


\section{THEORETICAL BACKGROUND, RESEARCH AIMS AND METHODS}

Social networks are social groups that (as a grouping form) consist of social actors but also imply interaction and social ties among them, and together make the social network, affording the channels for dissemination of messages, ideas, resources, knowledge and information (Crossley et al. 2015: 3). Social networks formed through internet communication are referred to as virtual groups or virtual communities. Personal offline social networks are maintained in most cases through face-to-face communication in everyday life ${ }^{2}-$ at home, at work, in the place of residence - but also include telephone communication, which could nowadays (displacing letters) also take place online through software products like Facebook, Viber, Google, WhatsApp, etc. Virtual social networks are very often based on the linking of people through the use of these apps and programs and are extended also in chat-forums, blogger-reader and further online platforms for communication.

Offline and online social networks could be analyzed from an overall community perspective (full-net) as well as from egocentric perspective (ego-net). Fundamental for both types are actors and relations. In the egocentric networks the individual - ego - is in the focus and the others - alteri - are the persons connected with the ego (see Schnegg \& Lang 2002: 35-39). British sociologist Christine Hine has introduced the method of virtual ethnography, which is "ethnography of, in and through the virtual - we learn about the Internet by immersing ourselves in it and conducting our ethnography using it, as well as talking with people about it, watching them use it and seeing it manifest in other social settings" (Hine 2004: 2).

Robert Kozinets's netnography, an interpretative method suitable for the study of internet users' behavior and online communities formed through computer-mediated communication $^{3}$ is also relevant for the research. Kosinets differentiates between communities-online and online-communities. The first one differs from the second one in that they exist not only on the web but also meet face to face. He defines the method studying such communities as blended ethnograhy (Kozinets 2010), i.e., a combination of virtual and real ethnography used for the study of very different social activities independent of the spatial boundaries. For online-communities the approach of the participant-experiencer is also suitable (Walstrom 2004); for example, by joining a Facebook group the researcher can actively publish comments and at the same time observe the communication of the other members. All these methods are applied to gather information needed for the study. Afterwards, written narratives and other text forms as well as all communication properties such as used vocabulary, 
shared personal opinions, standpoints and reality conceptions of the actors are studied through the method of content analysis (Jenkner 2007).

The main goal of this research is to analyze the personal social networks of Germans in Bulgaria and get an idea of the respondents' social circles (origin and place of residence of the people they contact the most, language of communication, etc.). The second aim is to give a brief description of the platformbased virtual community networks and their contribution to the formation and existence of German subgroups on the territory of Bulgaria.

Besides the classical ethnographic methods of interviewing, ${ }^{4}$ the methods of social network analysis, virtual ethnography and netnography were also applied in the research. Empirical data was gathered, on the one hand, through semi-structured interviews and, on the other hand, via a questionnaire sent to the respondents by e-mail. The first one covered topics concerning the reasons for migration and the migrants' adaptation in Bulgaria, their everyday life and festivities, their communication with family members, relatives, friends and other people in Germany and in Bulgaria. The questionnaire included questions on everyday activities with other people of their offline and online social networks. Regarding the questionnaire on the personal network, there were questions such as "With whom do you live?", "With whom do you drink coffee/ beer?", "Who do you ask to take care of your plants at home when you travel?", "Who repairs your PC?", "With whom do you travel to Germany? Who do you visit there?", "With whom do you watch football games on TV?", etc. The alteri tables contained questions regarding the age, nationality, place of residence of the people mentioned in the questionnaire as well as the type, duration, and intensity of the ego's relationship to them.

The number of interviewees was 40 ( 29 male and 11 female). Their age range was from 24 to 71 . Based on the activities, the respondents can be divided into students (1), workers (16), and pensioners (23).

\section{VIRTUAL SOCIAL COMMUNITIES}

One and maybe the biggest platform for the formation of virtual communities is InterNations: Your Expat Community in Sofia (2007). It numbers almost three million members with virtual communities in 390 world cities, including Sofia, and gives the opportunity, in a given city, to easily contact other compatriots outside the country of origin with the same interests or problems. At the end of January 2018, the German-oriented virtual community had ca. 180 members. ${ }^{5}$ Some of them take part in organized InterNations events and groups of interests in Sofia such as Sofia DinnerNations, Sofia City Trotters, Sofia Dancing 
Group, etc. After viewing the profiles of the users, it could be concluded that they are representatives of different age groups belonging to the category of labor migration.

Other newer and small-scale platforms for establishing new contacts and groups of interest are Deutsche in Bulgarien ${ }^{6}$ (Germans in Bulgaria) and Deutsche-Community ${ }^{7}$ (German-Community). These platforms allow inscribing also other Bulgarian towns besides Sofia, and, respectively, contacting other Germans living in the same region. On the whole, however, the number of the registered Germans is less than 20 (in a comparatively equal correlation of male and female).

The analysis shows that the most popular and most numerous among German immigrants in Bulgaria are the virtual groups in Facebook. Since the beginning of the research, August 2017, I have found 16 Facebook groups, related to the life of Germans in Bulgaria. The analysis of the members' profiles reveals that there are three types of members: people who have already immigrated to Bulgaria, people who have bought a house or an apartment and plan to leave Germany soon, and users who become members because they have considered the idea and made plans to settle down in Bulgaria, even without having ever visited the country. According to the stay duration, the groups could be categorized as permanent residents (living in Bulgaria all year round) and those temporarily visiting the country for several weeks or months per year.

Groups are ordered according to the number of members as of 20 August 2019:

- Bulgarien erLeben ${ }^{8}$ Experience Bulgaria), 3,045 members - the group is used as an interactive platform for people interested in Bulgaria as tourists, traders, current or future residents, etc.;

- Deutsche in der Kneipe: der deutsche Stammtisch in Sofia ${ }^{9}$ (Germans in the pub: German regulars in Sofia), 2,662 members - the location and date of the next regular meeting of the Germans in Sofia are determined in the group. Sometimes job offers for people with German language skills in Bulgaria are also posted;

- Auswanderer in Bulgarien - Hier werden Sie geholfen! Das Original ${ }^{10}$ (Immigrants in Bulgaria - Come here for help!), 2,044 members - the idea of the group administrator is to enable a space where information between immigrated people and non-migrants could be shared, such as, for example, positive and negative things in Bulgaria (donation actions for poor children and old people, etc.);

- Deutsche in Bulgarien ${ }^{11}$ (Germans in Bulgaria), 1,412 members - the group is, above all, for Germans who live or wish to live in Bulgaria. Similar to the other groups information is published about the positive 
and negative sides of Bulgaria, its sightseeing and holiday opportunities, etc.;

- Bulgarien - Auswandern ${ }^{12}$ (Bulgaria - Emigration), 1,307 members a group for useful hints, exchange of experience and facts about Bulgaria;

- I Love Burgas Deutschprachige Gruppe ${ }^{13}$ (I love Burgas Germanspeaking group), 991 members - publishing reports and news interesting for Germans and German-speaking people in the region of Burgas;

- Leben und Urlaub in Bulgarien ${ }^{14}$ (Life and holiday in Bulgaria), 533 members - a group to share hints, connected with the transfer of domicile or a holiday in Bulgaria;

- Ärzte in Bulgarien ${ }^{15}$ (Doctors in Bulgaria), 512 members - functions as a database for opinions and addresses of doctors (categorized by region and specialization) and circumstances (as, for example, the doctor's German language skills or payment options);

- \#Bulgarien info....... ${ }^{16}$ (\#Bulgarian info......), 421 members - the founders of the group invite everyone interested in a relaxed and free life style, building their own house, and in how "with less money one could realize their dreams the best", to share experience and ideas. The administrators regularly publish news about Bulgaria in German;

- Deutschsprachige in Bulgarien ${ }^{17}$ (German-speaking people in Bulgaria), 312 members - the group is formed for German-speaking people, who live or wish to live in Bulgaria or want to speak German;

- Bulgarien immer eine Reise wert ${ }^{18}$ (Bulgaria always worth a visit), 307 members - the posts include links to informative German booklets, photographs of Bulgaria showing the beauty and diversity that make the country worth a visit;

- Bulgarien (nur schönes) $)^{19}$ (Bulgaria (just good things)), 280 members similar to the previous group photographs and videos of beautiful Bulgarian landscapes are published, but also photographs of Bulgarian and German food or delicious vegetables and fruits grown in the country;

- Veranstaltungen in Bulgarien ${ }^{20}$ (Events in Bulgaria), 243 members a group for information about interesting events in Bulgaria, organized around Bulgarian or German holidays;

- Code Red Gruppe Bulgarien ${ }^{21}$ (Code Red Group Bulgaria), 225 members sharing bad experience with merchants and good practices to solve the problematic situations;

- Leseratten in Bulgarien - deutschsprachige Bücher - verleihen/ tauschen ${ }^{22}$ (Bookworms in Bulgaria - German books - give/exchange), 26 members; this Facebook group is for Germans, book fans in Bulgaria, searching for new books and sharing their own; 
- Happy Mädels-Tag Bulgarien ${ }^{23}$ (Happy girls' day Bulgaria), 20 members a group for an easier communication between the German-speaking women, meeting regularly in the region of Varna.

An overview of the posts, regarding the topics in the most numerous and most active group - Experience Bulgaria - shows a great variety. Very often the groups do not only share photographs and videos (also drone-videos) of nature landscapes and settlements, restaurants and resorts, but also temperature indicators or weather forecasts. The latter is one of the primary reasons for settling in Bulgaria - milder and less rainy weather in Bulgaria in comparison to Germany. Some of the posts concern logistics for the trip to Bulgaria (route, airlines, hotels, transport, sightseeing, Bulgarian restaurants), others - things in everyday life (for example, finding a mini-excavator; information about heating systems and materials, finding garden plants; how to direct the satellite to transmit German channels; shipment to and from Germany; prices of electricity, and so on).

There are Facebook groups of German students in Bulgaria for students in Sofia (Deutsche Studenten Medical University Sofia ${ }^{24}$ (German students Medical University Sofia)), Varna (Offizielle deutschsprachige Gruppe der MU-Varna ${ }^{25}$ (Official group of German-speaking medical students in Varna) and Deutsche Studenten in Varna ${ }^{26}$ (German students in Varna)) and Pleven (Deutsche Studenten MU Pleven ${ }^{27}$ (German students at the Medical University Pleven)), the biggest of which is the official German-speaking group of the Medical University in Varna, counting more than 500 members. The communication in the group is connected with different events and questions related to studies.

A content analysis of Facebook communication shows that there are some German-speaking women (more seldom men) in northeastern Bulgaria who spend most of their time or devote themselves entirely to caring for dogs and cats in need. They show concern for providing shelter and food for abandoned dogs on the street, for taking in, vaccination, and worming of homeless animals, regaining their health but also for finding new owners to them and organizing their transport even to Germany. They find new shelters for the animals by posting questions in German-speaking Facebook groups such as Tiermarkt - Bulgarien $^{28}$ (Animal market), Tiere aus Bulgarien sucht ein liebevolles Zuhause ${ }^{29}$ (Animals in Bulgaria search for a loving home; 360 members), Bulgariens Hunde in Not / Mitfahrgelegenheiten / Flugpaten / Spenden! ${ }^{30}$ (The Dogs of Bulgaria in need of / lift / flight sponsors / donation; 562 members) and others - as well as communicate with each other. Thus, a subgroup of German-speaking animal protectors has formed in northeastern Bulgaria, which is maintained through telephone calls, online chats, and physical meetings. 


\section{PERSONAL OFFLINE SOCIAL NETWORKS OF GERMANS IN BULGARIA}

The study of online social networks becomes more and more relevant as people spend plenty of time chatting, messaging, and publishing things through the online social media. However, people also continue to maintain their social relationships offline via telephone calls or regular meetings and visits. More information about the latter could be obtained by analyzing the ego's social network, which provides information about the presence and type of relationship with other people-family members, friends, colleagues, etc. - in everyday life and in the interaction with them mainly through face-to-face meetings (see also Schnegg \& Lang 2002).

This kind of analysis is only possible on the basis of the ego's answers about the alteri's demographic data (gender, age, place of residence, etc.) and about the type and intensity of the relationship they have with the latter. An overall social network includes egocentric networks of several individuals forming a given group (kinship, work team, community, etc.). The size, density, and centrality of the network play an important role in the study of community networks. Size is equal for all possible (also latent) ties, density expresses the potential communication between the single actors in the network, and centrality shows to what extent the ego has an access to other people in the network (Barova 2012: 227; see also Schnegg \& Lang 2002: 35-39). Owing to the possibility to illustrate location and relations between the actors, the network analysis is used also for the study of migration processes and social networks of single people, families and ethnic groups (see Barova 2012: 225; Bernardi 2011; Levitt \& Glick-Schiller 2004; Quirke \& Potter \& Conway 2009; etc.).

The analysis of personal social networks in this study is based on empirical data collected from seven Germans residing in Bulgaria. The data were obtained through a questionnaire that concerned the kinds of activities in the respondents' everyday life that required contact with people belonging to their social network. One of the respondents is a student, two respondents are pensioners, and four respondents are employees; they have resided in Bulgaria from three months to five years. Below I analyze the data of five respondents. As their networks give the most contrasting information, they are visualized with the help of the program VennMaker, ${ }^{31}$ which provides a possibility of mapping the personal social networks.

The personal social networks of the respondents (ego) and the people who belong to ego's social circle (alteri) are depicted in Figures 1-5. The ego is marked with a black circle; alteri are marked with circles with a gender marker or without a gender marker if they refer to a group of people. The continuous line indicates relationships with family and relatives as well as intimacy relationships; the broken line indicates friendship; the dotted line indicates an economic relationship. 


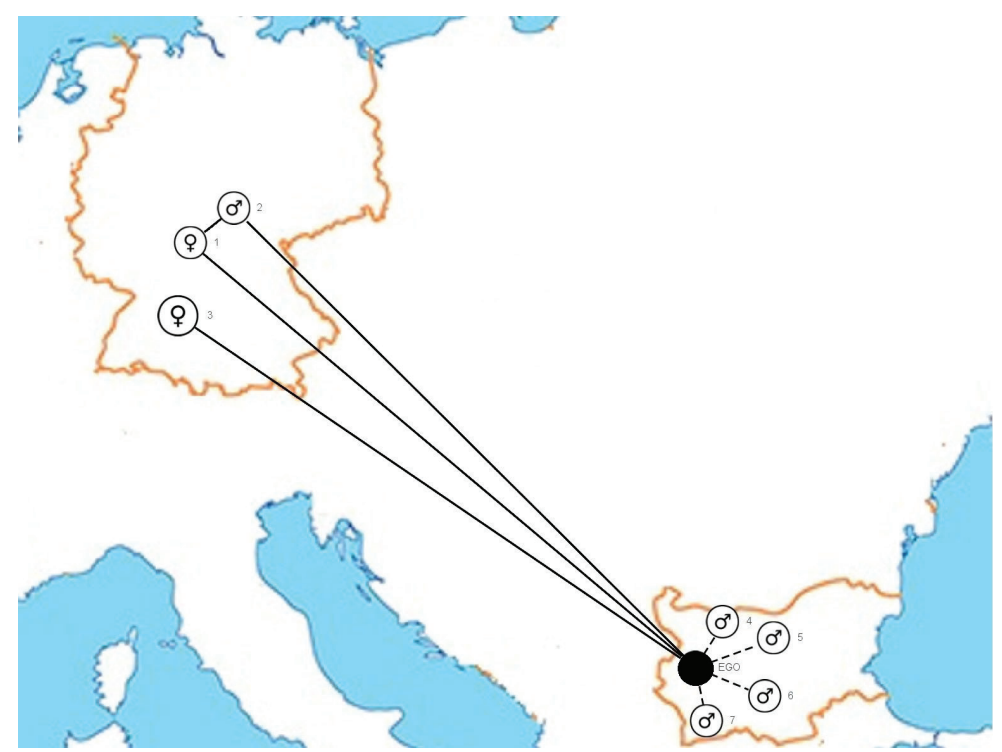

Figure 1. Personal social network of the ego J1 residing in Bulgaria. The network includes (a) one male and one female family member (parents), and an intimacy partner - girlfriend - living in Germany (as the ego is not married, his girlfriend is not connected with his parents); (b) four male friends living in Bulgaria.

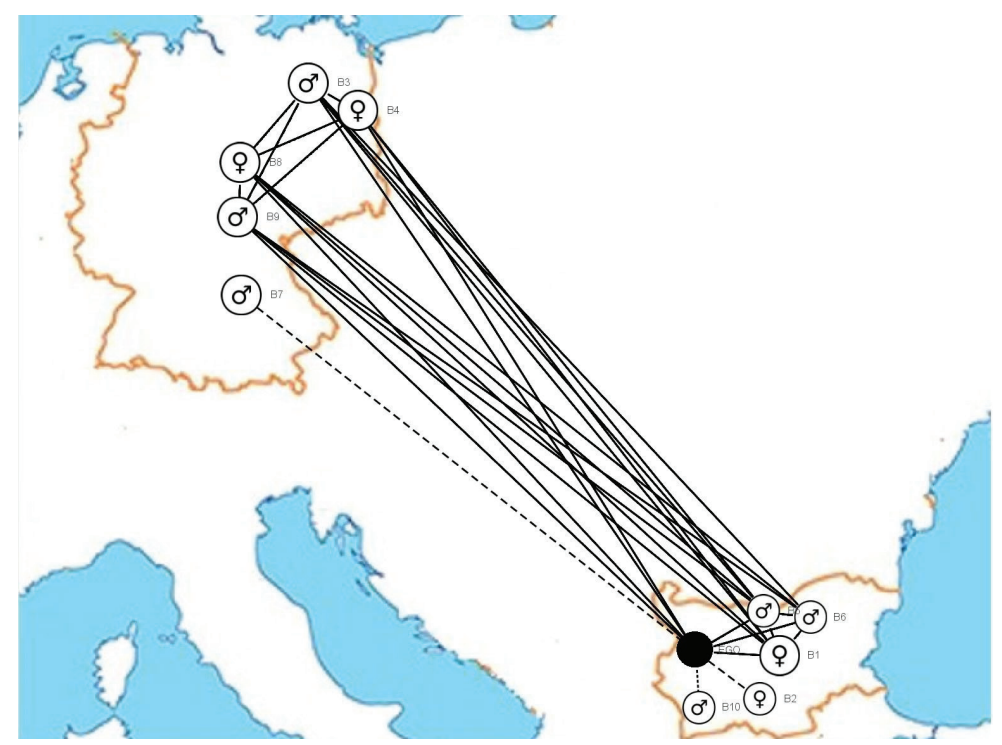

Figure 2. Personal social network of the ego C2 residing in Bulgaria. The network includes (a) one female and two male family members (the ego's wife and two sons); (b) one male with whom the ego has economic relationships; (c) one female friend - all of them are residing in Bulgaria; (d) two married couples (the ego's and his wife's parents); and (f) one male friend living in Germany. 


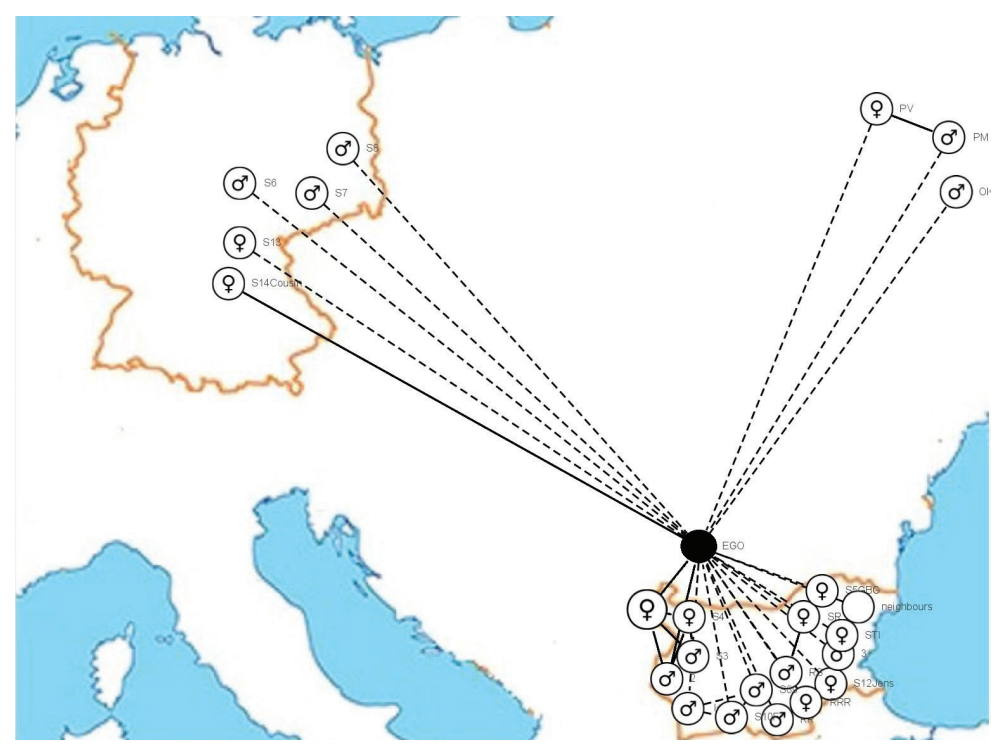

Figure 3. Personal social network of the ego $S 3$ residing in Bulgaria. The network includes (a) six male and five female friends; (b) two male and two female family members (wife, her brother, and parents) living in Bulgaria; (c) one female and three male friends; (d) one female family member (a cousin) living in Germany; (e) one female and two male friends who are Canadian residents.

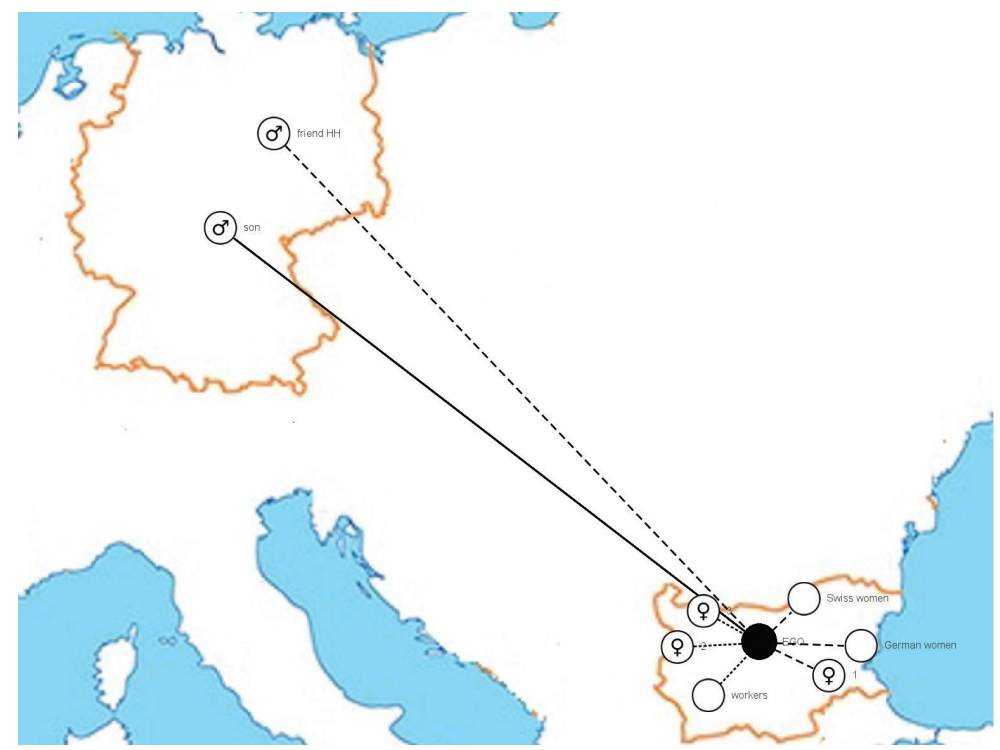

Figure 4. Personal social network of the ego A4 residing in Bulgaria. The network includes (a) two women and a group of Bulgarian workers with whom the ego has economic relationships; (b) two male friends living in Bulgaria; (c) one male family member (son), and one male (IT-specialist) living in Germany, with whom the ego has economic relationships. 


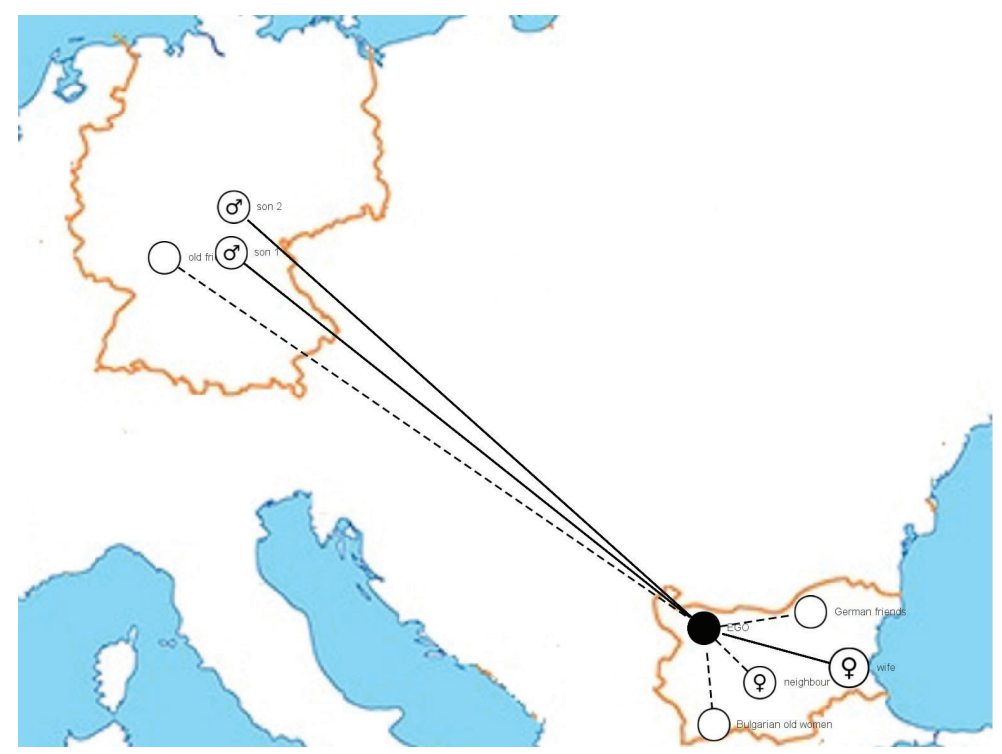

Figure 5. Personal social network of the ego K5 residing in Bulgaria. The network includes (a) one female family member (wife); (b) one female friend; (c) Bulgarian female friends belonging to one group; (d) German friends belonging to another group, all residing in Bulgaria; (e) two male family members (sons); and (f) a group of German friends, all residing in Germany.

Figures 1-5 presented above demonstrate the egos' communication with their alteri, focusing mainly on various types of relationships such as friendship, family and economic relationships; the figures also refer to the gender of the ego's social partners. However, the egos also interact with the alteri of various ethnic backgrounds and residing in different countries and on several continents. Figures 6-10 bring forth the egos' transnational and cross-border relationships.

Considering the people in the individual social networks, all respondents live with a German partner, except for the ego S3 (Fig. 8), who is married to a Bulgarian, and the single ego A4 (Fig. 9). In general, depending on their everyday needs, the egos mostly contact people who live in the same or a neighboring settlement. People in the country of origin are called either to be greeted on a holiday or just to chat; for example, old friends, who are visited during a journey to Germany. Often a person who does not live in Bulgaria is mentioned in the issues concerning problems with computer software, which could be tackled from every part of the world. On the whole, we see respondents who have just one or two Bulgarians in their closer ego-net (J1, Fig. 6, and C2, Fig. 7), while others stay in friendship and work relationships with native people in Bulgaria 
(S3, Fig. 8; K5, Fig. 10; and A4, Fig. 9). Figures 6, 8, and 9 show that the alteri are of Bulgarian-American, Canadian, Austrian, Swiss, and British origin. The ego A4 (female, Fig. 9) communicates with British and Swiss women in the region of her residence. The first is a friend of hers who waters her plants and feeds her dogs when she is away. With the Swiss women she meets regularly, once a month, to talk about different things. The ego S3 (male, Fig. 8) has contacts with Canadians in Canada for spiritual conversations. The Australian man of his ego-net lives in the same place (with a Bulgarian friend) and he is the person who he would ask to lend him money, if necessary. The ego J1 (male, Fig. 6) has some good contacts with Bulgarian Americans with whom he meets for a dinner, to drink a beer or to watch a movie.

Based on the fact that all these seven respondents do not belong to one group, their connectedness is presented through their membership in the abovementioned 16 Facebook groups of Germans in Bulgaria. Further interpersonal relationships are also mentioned in Figure 11.

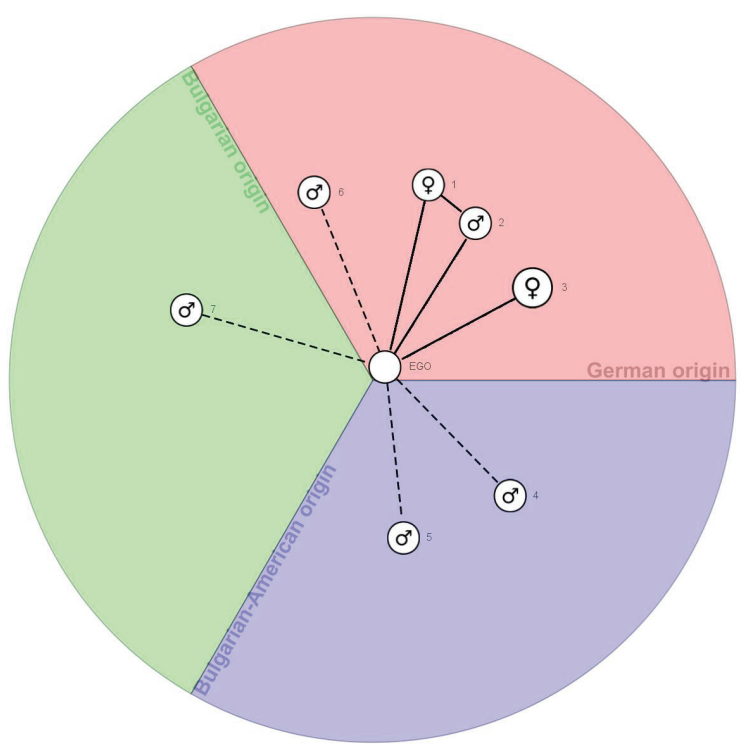

Figure 6. Personal social network of the ego J1 (cf. Fig. 1). The circle slices refer to the origin of the alteri: German, Bulgarian-American, and Bulgarian origin. 


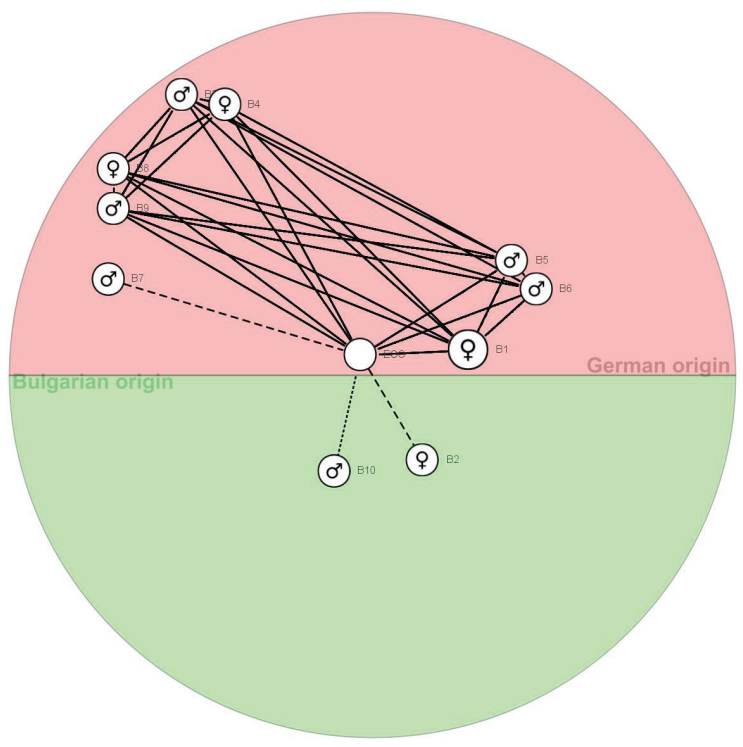

Figure 7. Personal social network of the ego C2 (cf. Fig. 2). Both circle slices refer to the origin of the alteri-German and Bulgarian.

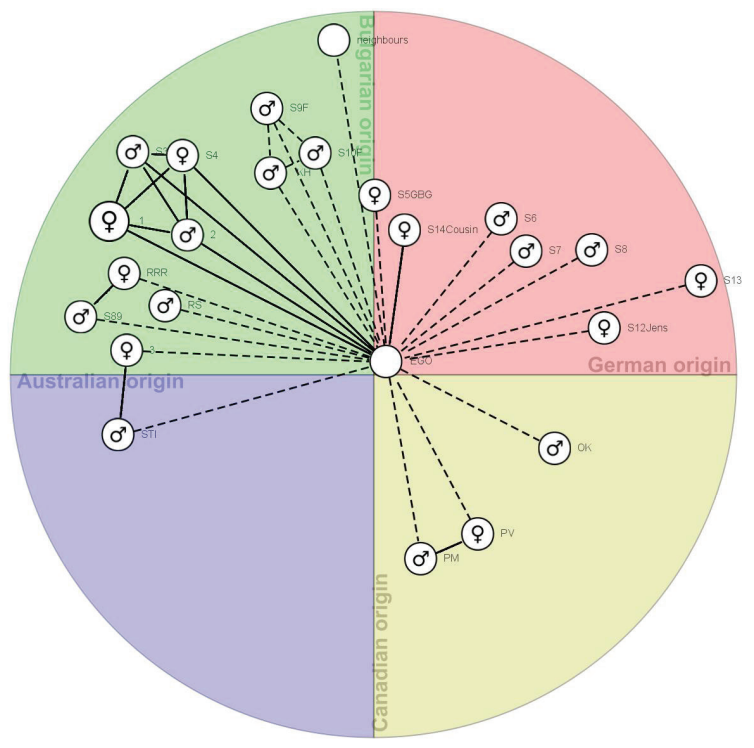

Figure 8. Personal social network of the ego S3 (cf. Fig. 3). The circle slices refer to the origin of the alteri-German, Canadian, Australian, and Bulgarian. 


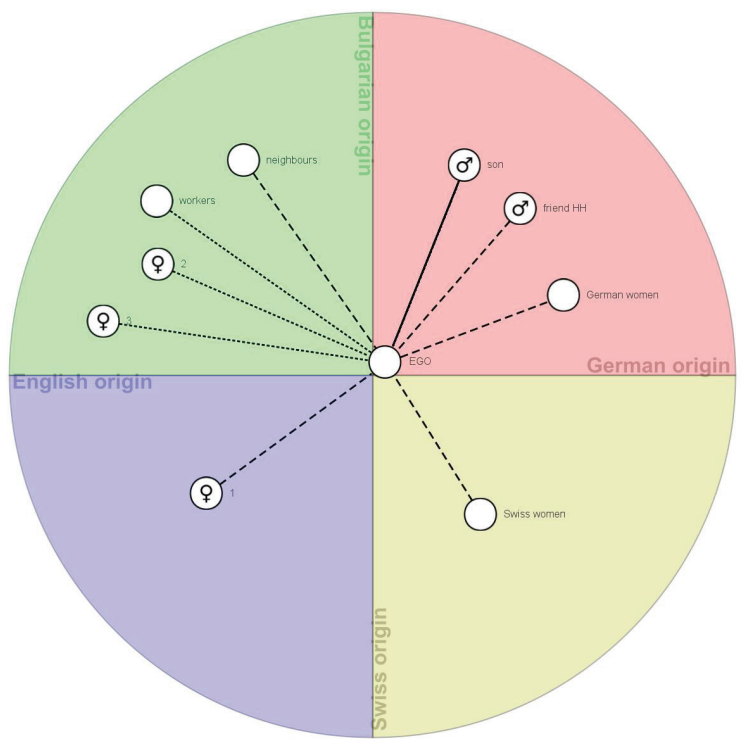

Figure 9. Personal social network of the ego A4 (cf. Fig. 4). The circle slices refer to the origin of the alteri-German, Swiss, English, and Bulgarian.

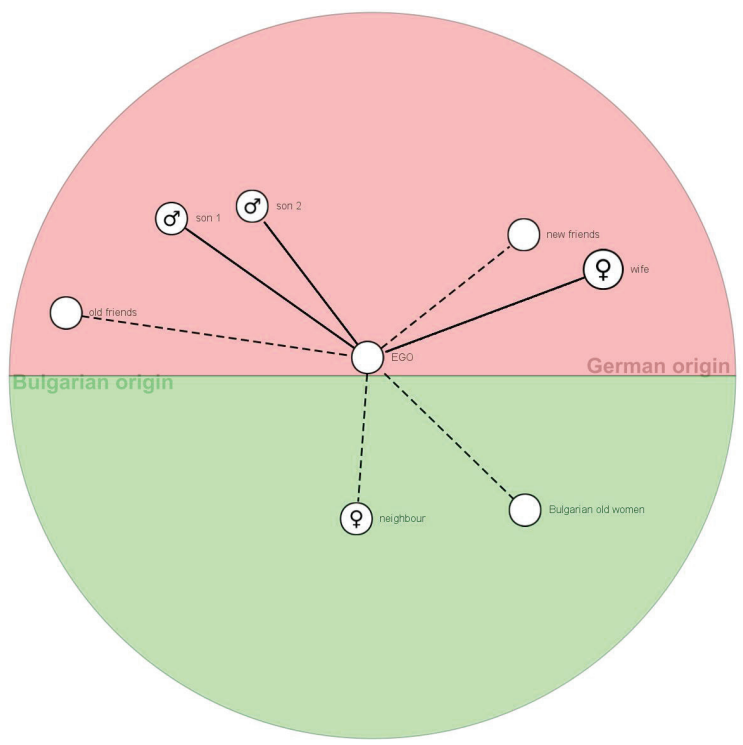

Figure 10. Personal social network of the ego K5 (cf. Fig. 5). Both circle slices refer to the origin of the alteri-German and Bulgarian. 


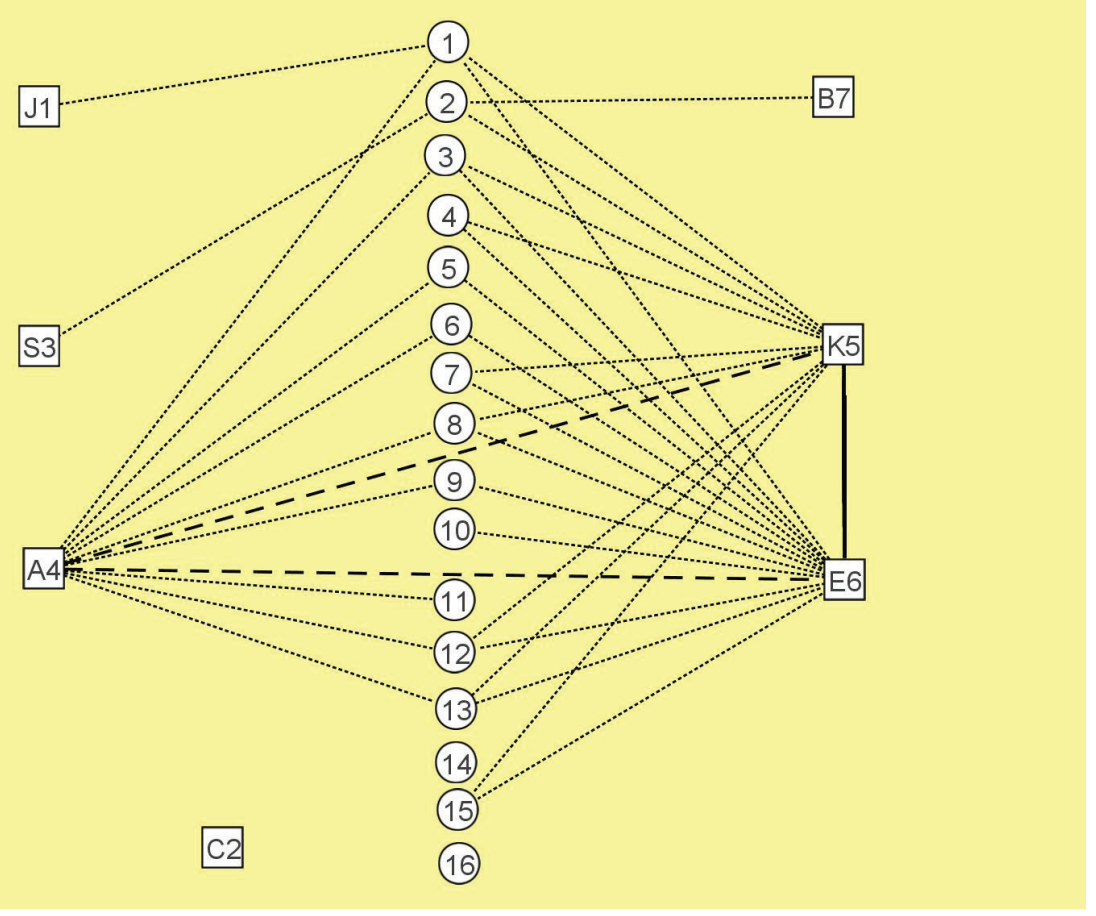

Figure 11. The figure demonstrates online and offline connectedness of the respondents with analyzed social networks of the egos J1, C2, S3, A4, K5, E6, and B7. The continuous line refers to a family relationship, the broken line refers to offline relationships, and dotted lines refer to membership in the Facebook groups of Germans in Bulgaria (1-16).

Figure 11 reveals that all the analyzed respondents, except C2, have a Facebook account; however, $\mathrm{C} 2$ is included in the graphic because he is one of the seven people who gave information about his social network and because this highlights that not everyone uses Facebook in their life. While the respondents J1, B7, and S3 are members in just one group, A4, K5 and E6 are group administrators or participate actively in more than one group. Two of them build a family and friendship with the third one not only virtually but also in the real space, which one of the respondents associates with the possibility "to see the faces of some of the Facebook friends"32. Neither K5 nor E6 mention A4 in their answers to the questions regarding their social networks. C2 is in the age group of 40-50-year-old people; he works at the German embassy in Sofia and went to Bulgaria after receiving a job contract there. As opposed to the other analyzed respondents, he communicates with relatives and friends by telephone calls or WhatsApp. 


\section{CONCLUSION}

In general, gathering empirical data for a social network analysis is not an easy task. On the one hand, it very much depends on the relationship between the researcher and the respondent and interviewees are not always willing to fill out questionnaires and alteri tables about their life and social networks. On the other hand, even if such information is obtained, it is one-sided because it includes just the offline ego-nets. Facebook ego-nets and other ego-centered virtual networks can only be analyzed in cooperation with the respondents. However, it could be concluded that Germans in Bulgaria have close contacts with their compatriots in Bulgaria. In regions with more numerous German presence the Auswanderer organize group meetings several times a year, which are visited by Germans searching for people with whom they could speak in German about things related to their life in Bulgaria, their homeland, their families, their pets, etc. The Bulgarian language is used mainly in situations of face-to-face communication by the Germans having Bulgarian friends or co-workers but also for interaction with neighbors. In the respondents' social circles people of German origin (living in Germany, Bulgaria or other countries) dominate, followed by Bulgarians and other ethnicities. Regarding the density of the social circles all but one are less compact as the alteri do not communicate among each other. It is only the respondent with a social circle visible in Figures 2 and 7 who has a denser social network because of the many relationships among family members.

After the Facebook company discontinued the applications for the visualization of social networks such as TouchGraph and NameGenWeb, a graphic of a group social network could hardly be made just by one click. At the same time, Facebook groups are the most accessible for the analysis of group networks; however, it is very time-consuming and possible only with the help of the methods of participant-experience and blended ethnography. The Facebook groups of Germans in Bulgaria are not only numerous (16 groups) but also with a large number of participants (in some groups there are more than 2,000 members). While some members prefer to have fewer groups but specified by regions of residence, the current groups provide them with the opportunity to communicate in their native language, find compatriots, exchange experiences and useful hints. Furthermore, this is the main space in which Germans present their reflections, impressions, and experiences in and about their new place of residence. While two of the groups have been created to share information about events related to the Germans in Bulgaria, but also about Bulgarian folklore and cultural landscapes, or to facilitate the communication and the organization of gatherings in the real (offline) world (the so-called Stammtische), the 
other groups could be labeled as communities-online (however, in some cases meetings in the real world are also initiated virtually). What they all have in common is that they unite the Germans who search contact with compatriots, with subgroups who meet regularly in the given regions in Bulgaria. In consequence, the built subgroups' networks provide a kind of a "native" space, helpful for the first months of adaption and also for integration in the new place of residence, a part of which is also the maintenance of their own ethnic and cultural identity based on communication in the native language, sharing native cuisine, attending Stammtische, and celebrating holidays in a German way.

\section{ACKNOWLEDGEMENTS}

Materials for the article were gathered within the framework of the project "Germans in Bulgaria: Community Institutions, Social Networks, Everyday Life” (2017-2019), funded by the Bulgarian Academy of Sciences.

\section{NOTES}

1 It should be noted that all the respondents preferred to use the word Auswanderer and not emigrant or expat for their self-determination.

${ }^{2}$ Everyday life includes also feasts, trips, and other actions characteristic of the individual's annual life cycle.

3 These online-communities are a product of the grouping of people with common interests. Differently from them, the traditional communities are locally more independent because thanks to the social media the interpersonal ties could be maintained also at great distances. Moreover, there are online-communities, formed as an additional space for the activities of groups existing in the real world, as, for example, of cultural organizations, clubs, etc., who use the social network platforms for the maintenance of their collectiveness (Greshke 2007).

4 Interviews conducted during the project "Germans in Bulgaria: Community Institutions, Social Networks, Everyday Culture" (2017-2019) are archived at the National Center for Intangible Heritage at the Institute for Ethnology and Folklore Studies at the Bulgarian Academy of Sciences, with archive numbers FnAIF (audio archive) No. 2969 and FnAIF No. 2986.

5 InterNations: Your Expat Community in Sofia. Available at https://www.internations. org/sofia-expats, last accessed on 20 April 2020.

${ }^{6}$ Deutsche in Bulgarien. Available at http://www.deutsche-in-bulgarien.com/, last accessed on 20 April 2020. 
7 Deutsche-community.com. Available at https://www.deutsche-community.com/, last accessed on 20 April 2020.

8 Bulgarien erLeben. Available at https://www.facebook.com/groups/bulgarien.erleben/, last accessed on 20 April 2020.

9 Deutsche in der Kneipe: der deutsche Stammtisch in Sofia, Bulgarien. Available at https://www.facebook.com/groups/deutsch.in.der.kneipe/, last accessed on 20 April 2020 .

${ }^{10}$ Auswanderer in Bulgarien - Hier werden Sie geholfen! Das Original. Available at https://www.facebook.com/groups/429564820504913/, last accessed on 20 April 2020.

${ }^{11}$ Deutschein Bulgarien. Available athttps://www.facebook.com/groups/455765038101225/, last accessed on 20 April 2020.

12 Bulgarien - Auswandern. Available at https://www.facebook.com/ groups/999508343432526/, last accessed on 20 April 2020.

${ }^{13}$ I Love Burgas Deutschprachige Gruppe. Available at https://www.facebook.com/ groups/218642458296887/, last accessed on 20 April 2020.

${ }^{14}$ Leben und Urlaub in Bulgarien. Available at https://www.facebook.com/ groups/1589222254644034/?ref=br_rs, last accessed on 20 April 2020.

15 Ärzte in Bulgarien. Available at https://www.facebook.com/groups/335296979944792/, last accessed on 20 April 2020.

16 \#Bulgarien info...... Available at https://www.facebook.com/groups/1814229532137058/, last accessed on 20 April 2020.

${ }^{17}$ Deutschsprachige in Bulgarien. Available at https://www.facebook.com/ groups/425562260831378/, last accessed on 20 April 2020.

${ }^{18}$ Bulgarien immer eine Reise wert. Available at https://www.facebook.com/ groups/1882215095376442/, last accessed on 20 April 2020.

${ }^{19}$ Bulgarien (nur schönes). Available at https://www.facebook.com/groups/bulgarien2014/, last accessed on 20 April 2020.

${ }^{20}$ Veranstaltungen in Bulgarien. Available at https://www.facebook.com/ groups/602231943206300/, last accessed on 20 April 2020.

${ }^{21}$ Code Red Gruppe Bulgarien. Available at https://www.facebook.com/ groups/576747586021620/, last accessed on 20 April 2020.

${ }^{22}$ Leseratten in Bulgarien - deutschsprachige Bücher - verleihen/tauschen. Available at https://www.facebook.com/groups/436780543360868/, last accessed on 20 April 2020.

${ }^{23}$ Happy Mädels-Tag Bulgarien. Available at https://www.facebook.com/ groups/498375587229773/, last accessed on 20 April 2020.

${ }^{24}$ Deutsche Studenten Medical University Sofia. Available at https://www.facebook.com/ groups/1065888540134506/?fref=nf, last accessed on 20 April 2020. 
${ }^{25}$ Offizielle deutschsprachige Gruppe der MU-Varna. Available at https://www.facebook. com/groups/1448613485427818/, last accessed on 20 April 2020.

${ }^{26}$ Deutsche Studenten in Varna. Available at https://www.facebook.com/ groups/975488159318764/, last accessed on 20 April 2020.

${ }^{27}$ Deutsche Studenten MU Pleven. Available at https://www.facebook.com/ groups/896745257020065/, last accessed on 20 April 2020.

${ }^{28}$ Tierfreunde - Bulgarien. Available at https://www.facebook.com/ groups/1697002470577166/, last accessed on 20 April 2020.

${ }^{29}$ Tiere aus Bulgarien sucht ein liebevolles Zuhause. Available at https://www.facebook. com/groups/737809696271990/?ref=br_rs, last accessed on 20 April 2020.

${ }^{30}$ Bulgariens Hunde in Not /Mitfahrgelegenheiten/Flugpaten/Spenden! Available at https://www.facebook.com/groups/290765080978591/, 562 members, last accessed on 20 April 2020.

31 The program VennMaker allows a description of the models of personal interrelations. It makes possible the visualization of social ties from the personal perspective of a respondent (ego) to other people (alteri) of their social environment, which could be subsequently analyzed comparatively and quantitatively.

${ }^{32}$ Facebook profile of A4.

\section{REFERENCES}

Barova, Vihra 2012. Prilozhenieto na mrezhoviia analiz v etnologichnoto izsledvane narodstvoto. [The Appliance of Network Analysis in the Ethnologic Study on Kinship.] In: Ana Luleva \& Valentina Vaseva \& Ivanka Petrova \& Petko Hristov (eds.) Etnologiiata v B"lgariia - istoriia, metodi, problemi. [Ethnology in Bulgaria History, Methods, Problems.] Sofia: AI "Prof. Marin Drinov", pp. 224-230.

Bernardi, Laura 2011. A Mixed-Method Social Networks Study Design for Research on Transnational Families. Journal of Marriage and Family, Vol. 73, No. 4, pp. 788-803. http://dx.doi.org/10.1111/j.1741-3737.2011.00845.x.

Crossley, Nick \& Bellotti, Elisa \& Edwards, Gemma \& Everett, Martin G. \& Koskinen, Johan Henrik \& Tranmer, Mark 2015. Social Network Analysis for Ego-Nets: Social Network Analysis for Actor-Centred Networks. London: Sage Publications.

Entzinger, Han \& Biezeveld, Renske 2003. Brenchmarking in Immigrant Integration. Rotterdam: European Commission. Available at https://ec.europa.eu/migrantintegration/librarydoc/benchmarking-in-immigrant-integration, last accessed on 20 April 2020.

Greshke, Heike M. 2007. Bin ich drin?-Methodologische Reflexionen zur ethnographischen Forschung in einem plurilokalen computervermittelten Feld. Forum: Qualitative Social Research, Vol. 8, No. 3. Available at http://www.qualitative-research.net/ index.php/fqs/article/view/279/613, last accessed on 20 April 2020. 
Hine, Christine M. 2004. Virtual Ethnography Revisited. Paper summary prepared for session on Online Research Methods, Research Methods Festival, Oxford, July 1st 2004. Available at http://www.restore.ac.uk/orm/background/exploringorms/ rmf_hine_outline.pdf, last accessed on 8 May 2020.

Immigrants 2017 = More Than a Quarter of the Immigrants in Bulgaria Are from Russia. Novinete.com, 15 December. Available at https://www.novinite.com/ articles/186288/More+than+a+Quarter+of+the+Immigrants+in+Bulgaria+are+ from+Russia, last accessed on 20 April 2020.

Jenkner, Jens 2007. Kurzdefinition und wissenschaftliche Praxis. QUASUS: Qualitatives Methodenportal zur Qualitativen Sozial-, Unterrichts- und Schulforschung. Available at https://quasus.ph-freiburg.de/1-kurzdefinition-und-wissenschaftlichepraxis/, last accessed on 20 April 2020.

Kozinets, Robert V. 2010. Netnography: Doing Ethnographic Research Online. Los Angeles \& London \& Washington \& New Delhi \& Singapore: SAGE Publications.

Levitt, Peggy \& Glick-Schiller, Nina 2004. Conceptualizing Simultaneity: A Transnational Social Field Perspective on Society. The International Migration Review, Vol. 38, No. 3, pp. 1002-1039. https://doi.org/10.1111/j.1747-7379.2004.tb00227.x.

Maeva, Mila 2017. B"lgarskite emigranti v Angliia - minalo i s"vremennost. [Bulgarian Emigrants in England: Past and Present.] Sofia: Paradigma.

Matanova, Tanya 2019. Deutsche in Bulgarien: Gemeinschaftsinstitutionen, soziale Netzwerke, Alltagskultur. Sofia: Paradima.

Quirke, Ellen \& Potter, Robert B. \& Conway, Dennis 2009. Transnationalism and the Second-Generation Caribbean Community in Britain. Geographical Paper No. 187. Reading: The University of Reading. Available at https://www.reading.ac.uk/web/ files/geographyandenvironmentalscience/GP187.pdf, last accessed on 20 April 2020 .

Schnegg, Michael \& Lang, Hartmut 2002. Die Netzwerkanalyse: Eine praxisorientierte Einführung. Methoden der Ethnographie, Heft 1. Available at https://www. researchgate.net/publication/275041134_Die_Netzwerkanalyse_Eine_ praxisorientierte_Einfuhrung, last accessed on 20 April 2020.

Walstrom, Mary K. 2004. "Seeing and Sensing" Online Interaction: An Interpretive Interactionist Approach to USENET Support Group Research. In: Mark D. Johns \& Shing-Ling Sarina Chen \& G. Jon Hall (eds.) Online Social Research: Methods, Issues, and Ethics. New York: Peter Lang, pp. 81-97.

Tanya Matanova is Assistant Professor $(\mathrm{PhD})$ at the Institute of Ethnology and Folklore Studies with Ethnographic Museum at the Bulgarian Academy of Sciences, Bulgaria. Her main research areas are ethnology of food, ethnology of migration, descendants of mixed marriages, Bulgarians' pilgrimages, and cultural heritage.

tanya.matanova@iefem.bas.bg 